\title{
Sarcopenic obesity and complex interventions with nutrition and exercise in community-dwelling older persons - a narrative review
}

This article was published in the following Dove Press journal:

Clinical Interventions in Aging

6 August 2015

Number of times this article has been viewed

\author{
Sabine Goisser' \\ Wolfgang Kemmler ${ }^{2}$ \\ Simone Porzel ${ }^{3}$ \\ Dorothee Volkert' \\ Cornel Christian Sieber ${ }^{1,4}$ \\ Leo Cornelius Bollheimer ${ }^{1,4}$ \\ Ellen Freiberger' \\ 'Institute for Biomedicine of \\ Aging (IBA), Friedrich-Alexander- \\ Universität (FAU) Erlangen-Nürnberg, \\ Nuremberg, ${ }^{2}$ Institute of Medical \\ Physics (IMP), Friedrich-Alexander- \\ Universität (FAU) Erlangen-Nürnberg, \\ ${ }^{3}$ Nutricia GmbH, Danone Medical \\ Nutrition, Erlangen, ${ }^{4}$ Department of \\ Internal Medicine and Geriatrics, St \\ John of God Hospital (Barmherzige \\ Brüder), Regensburg, Germany
}

Correspondence: Sabine Goisser Institute for Biomedicine of Aging (IBA), Friedrich-Alexander-Universität (FAU) Erlangen-Nürnberg, Kobergerstraße 60, D-90408 Nuremberg, Germany Email sabinegoisser@mail.de

\begin{abstract}
One of the many threats to independent life is the age-related loss of muscle mass and muscle function commonly referred to as sarcopenia. Another important health risk in old age leading to functional decline is obesity. Obesity prevalence in older persons is increasing, and like sarcopenia, severe obesity has been consistently associated with several negative health outcomes, disabilities, falls, and mobility limitations. Both sarcopenia and obesity pose a health risk for older persons per se, but in combination, they synergistically increase the risk for negative health outcomes and an earlier onset of disability. This combination of sarcopenia and obesity is commonly referred to as sarcopenic obesity. The present narrative review reports the current knowledge on the effects of complex interventions containing nutrition and exercise interventions in community-dwelling older persons with sarcopenic obesity. To date, several complex interventions with different outcomes have been conducted and have shown promise in counteracting either sarcopenia or obesity, but only a few studies have addressed the complex syndrome of sarcopenic obesity. Strong evidence exists on exercise interventions in sarcopenia, especially on strength training, and for obese older persons, strength exercise in combination with a dietary weight loss intervention demonstrated positive effects on muscle function and body fat. The differences in study protocols and target populations make it impossible at the moment to extract data for a meta-analysis or give state-of-the-art recommendations based on reliable evidence. A conclusion that can be drawn from this narrative review is that more exercise programs containing strength and aerobic exercise in combination with dietary interventions including a supervised weight loss program and/or protein supplements should be conducted in order to investigate possible positive effects on sarcopenic obesity.
\end{abstract}

Keywords: sarcopenia, obesity, mobility, nutrition, weight loss diets, exercise, review, function

\section{Introduction}

Maintaining independence, quality of life, high function, and health is crucial for the older population, and with the ongoing demographic changes, it is also of utmost importance for all Western societies. It is thus essential for the sustenance of the public health care systems to evolve concepts and support strategies that increase older persons' period of independent living.

One of the many threats to independent life is the age-related loss of muscle mass and muscle function referred to as sarcopenia. ${ }^{1-3}$ Sarcopenia can lead to functional impairments and mobility limitations, which are related to other geriatric syndromes such as propensity of falls and immobility, ${ }^{4,5}$ thus leading to disabilities in older persons. $^{6-9}$

Another important health risk in old age leading to functional decline is obesity. ${ }^{10,11}$ Obesity prevalence is increasing in the older population, and like sarcopenia, obesity 
(ie, a body mass index (BMI) $>30 \mathrm{~kg} / \mathrm{m}^{2}$ ) and severe obesity (ie, a BMI $>35 \mathrm{~kg} / \mathrm{m}^{2}$ ) have been consistently associated with several negative health outcomes, disabilities, falls, and mobility limitations. ${ }^{12-17}$ The effect of obesity on mortality by cardiovascular disease, however, is less relevant in older than in younger age groups, ${ }^{18}$ as obese older patients with cardiovascular disease have demonstrated better survival rates compared with nonobese older patients (the so-called “obesity paradox"). ${ }^{15,18-20}$ But even if mortality rates might be affected positively by obesity, the problem remains that its negative effects on function may lead to considerable disability during this extended lifetime. ${ }^{16,18,19,21,22}$

Both sarcopenia and obesity pose a health risk for older persons per se, but it has been shown that in combination they synergistically increase the risk of negative health outcomes and earlier onset of disability. ${ }^{8,11,23,24}$ This combination of sarcopenia and obesity is commonly referred to as sarcopenic obesity (SO). ${ }^{17}$ For example, Rolland et a ${ }^{11}$ found in a landmark study in an older female cohort an odds ratio (OR) of 1.47 for impaired function (climbing stairs) for women with sarcopenia compared with healthy peers, an OR of 1.79 for purely obese women, but an OR of 3.60 for sarcopenic obese women.

Depending on the definition used (see "Definitions" section), a prevalence of SO between $4 \%$ and $20 \%$ has been estimated in the general older population. ${ }^{23,25} \mathrm{New}$ data from the third National Health and Nutrition Examination Survey (NHANES III) estimated the overall prevalence of sarcopenia as $35 \%$ in women and $75 \%$ in men, which increased with age. ${ }^{26}$ The prevalence of obesity based on percent fat mass was $61 \%$ and $54 \%$, respectively. SO prevalence was even estimated as $18 \%$ in women and $43 \%$ in men, and also increasing with age. ${ }^{26}$

In view of the previously mentioned high risk of adverse health outcomes, it is important to address SO, and effective interventions are warranted. The present narrative review reports the current knowledge on the effects of complex interventions containing nutrition and exercise components in community-dwelling older persons with SO. In case of lack of evidence on SO, the current understanding for both single entities - sarcopenia and obesity - is presented separately. Furthermore, we will discuss future options to counteract SO with such nonpharmacological interventions.

\section{Definitions}

Research on SO began only recently with the growing insight that both sarcopenia and obesity seem to share common etiological pathways, ${ }^{17,27}$ but so far has been hampered by the lack of clear definitions and cutoff values for all three entities and the resulting considerable heterogeneity of population characteristics. ${ }^{17,24,28,29}$

\section{Obesity}

Obesity is the term for extensive body fat mass accumulation. ${ }^{30}$ Independent of age, the World Health Organization (WHO) defines obesity as BMI $>30 \mathrm{~kg} / \mathrm{m}^{2}$, and central obesity as waist circumference $>102 \mathrm{~cm}$ in men and $>88 \mathrm{~cm}$ in women. ${ }^{30}$ It is currently under discussion whether use of percentage body fat mass or waist circumference (as surrogate parameter for visceral fat mass) would be more appropriate for defining obesity. ${ }^{12,20,22,31}$ However, although deemed necessary, so far no separate cutoff values for BMI, waist circumference, or percentage of body fat mass for classification of overweight and obesity have been defined for older adults. ${ }^{15,20}$

\section{Sarcopenia}

Earlier definitions of sarcopenia focused on the age-dependent loss of muscle mass alone, ${ }^{32}$ but updated definitions and consensus statements are now taking into account that the loss of age-related muscle mass is not in parallel with the rate of strength decline in older age. ${ }^{33}$ Therefore, the up-to-date consensus definition of sarcopenia is "loss of skeletal muscle mass and muscle function" exceeding the normal age-dependent development, ${ }^{1,3,34,35}$ although there are other approaches that remain based on the assessment of muscle mass alone. ${ }^{36}$ As there is also a plethora of different methods used to assess muscle mass (eg, dual energy X-ray absorptiometry or bioimpedance analysis $)^{1,33,34}$ and varying approaches to analyze the results of such measurements (eg, "classic" bioimpedance analysis or bioimpedance vector analysis), ${ }^{36}$ not to mention the use of different cutoff values to define sarcopenia in different studies, to date poor consistency between the results from different studies is frequent. Muscle function may be determined by performance (eg, gait speed) and/or strength (eg, handgrip strength) measures, ${ }^{1,33,34}$ but also in this case, the diversity of methods and cutoff values employed impedes study comparability.

\section{Sarcopenic obesity}

SO is considered to be a combination of sarcopenia (decreased muscle mass and function) and obesity (excess body fat mass) ${ }^{17}$ However, considering the previously mentioned problems regarding criteria for obesity and sarcopenia alone, it is no surprise that a widely accepted specific definition of SO to date does not exist. Accordingly, 
the prevalence of SO is reported to range from $4 \%$ to $84 \%$ in men and from $4 \%$ to $94 \%$ in women, depending on the current research definition employed. ${ }^{29}$ Many of the currently used definitions for SO focus on muscle mass alone, while only a few take into account functional criteria. ${ }^{24,28,36}$ Moreover, some studies employ terms like "(physically) frail obese elderly" ${ }^{\prime 2,31,37}$ and use different criteria for the definition of frailty not comparable to current criteria for sarcopenia. This adds further confusion to the already heterogeneous field of SO definitions and cutoff values, and contributes to the currently seen poor consistency of results.

\section{Physical activity, physical fitness, and exercise}

Caspersen et $\mathrm{al}^{38}$ have developed terminology for physical activity (PA) and exercise for different professions that has been endorsed by the WHO recommendations for PA. ${ }^{39}$ According to this recommendation, PA is defined as any bodily movement produced by skeletal muscles that results in energy expenditure, whereas exercise is a subset of PA that is planned, structured, repetitive and has the objective of improving or maintaining physical fitness. Physical fitness is defined as a set of attributes related either to health components or specific skills. ${ }^{38}$ Health-related physical fitness components are level of endurance, strength, flexibility, and body composition including body fat percentage and lean muscle mass. Exercise training (ET) for health and function in older persons consists of different components: strength (or resistance) and power training, aerobic exercise, flexibility and balance/gait training. ${ }^{40,41}$ Elements of strength/power training are volume (eg, number of repetitions), frequency (eg, number of training sessions per week), and intensity (percentage of one repetition maximum). ${ }^{42}$ Aerobic exercise is responsible for cardiovascular fitness and describes the ability to perform dynamic, moderate-to-vigorous exercise over a long period of time involving large muscle groups, as, eg, walking or cycling. Aerobic exercise depends primarily on oxygen consumption through aerobic metabolism. ${ }^{40}$ Flexibility is the ability to move with a wide range of motion through a joint, and balance and gait training is important for fall prevention and enhancing mobility. ${ }^{40}$

\section{Nutritional intervention}

Nutrition is a broad term referring to food, its science, and to the whole process of selection, preparation, and ingestion of foods and the contained nutrients (chemical compounds with a potential function in the body) as well as their action and interactions in relation to health and disease (WHO e-Library eLENA, accessible at www.who.int/elena). In nutrition, diet generally refers to the sum and kinds of foods that are habitually consumed (from Greek diaita: "a way of life"). The word diet is sometimes also used for interventions aiming at a specific intake, reduction or avoidance of certain nutrients, mainly for health or weight management reasons. Most nutritional (or dietary) interventions are behavioral, ie, advice on a particular diet or on certain dietary changes is given with the aim of changing a subject's dietary intake in a certain way. Supplementation of single nutrients or a nutrient combination in addition to the regular diet can be used complementarily or alternatively (WHO e-Library eLENA).

\section{Complex interventions}

The term "complex intervention" was recently updated by the Medical Research Council. ${ }^{43}$ Complex interventions include several interacting components, eg, the behavioral qualification of those providing the intervention, number of groups or organizational levels targeted by the intervention as well as number and variability of outcomes. ${ }^{43}$

\section{Self-efficacy}

Self-efficacy is a person's perception of her or his individual personal capacity within particular domains of activities. ${ }^{44}$

\section{Pathways to sarcopenic obesity}

Several different mechanisms are thought to lead to SO. Although a unanimous view on the etiology of SO has not yet been established, ${ }^{24,28}$ several of the common age-related factors discussed as contributing to the development of sarcopenia and obesity are depicted in Figure 1, among them increase in inflammatory processes, increase of insulin resistance, and sex-specific decrease of hormones such as androgen and growth hormone..$^{27,45,46}$ In addition, behavioral factors such as decline in PA and inappropriate food consumption can be important contributing factors. ${ }^{17,23,46-49}$ As Figure 1 illustrates, some factors are only related to sarcopenia or obesity alone, whereas other factors are common to both syndromes. Besides the congruent pathways, effective interventions should also address the stand-alone contributors for sarcopenia or obesity. This multitude of factors highlights the need for complex interventions to counteract SO in the most effective way.

\section{Role of physical activity and nutrition in the etiology and therapy of sarcopenic obesity}

Two lifestyle factors play a major role in the development of sarcopenia, obesity, and SO: PA and nutrition. Figure 2 

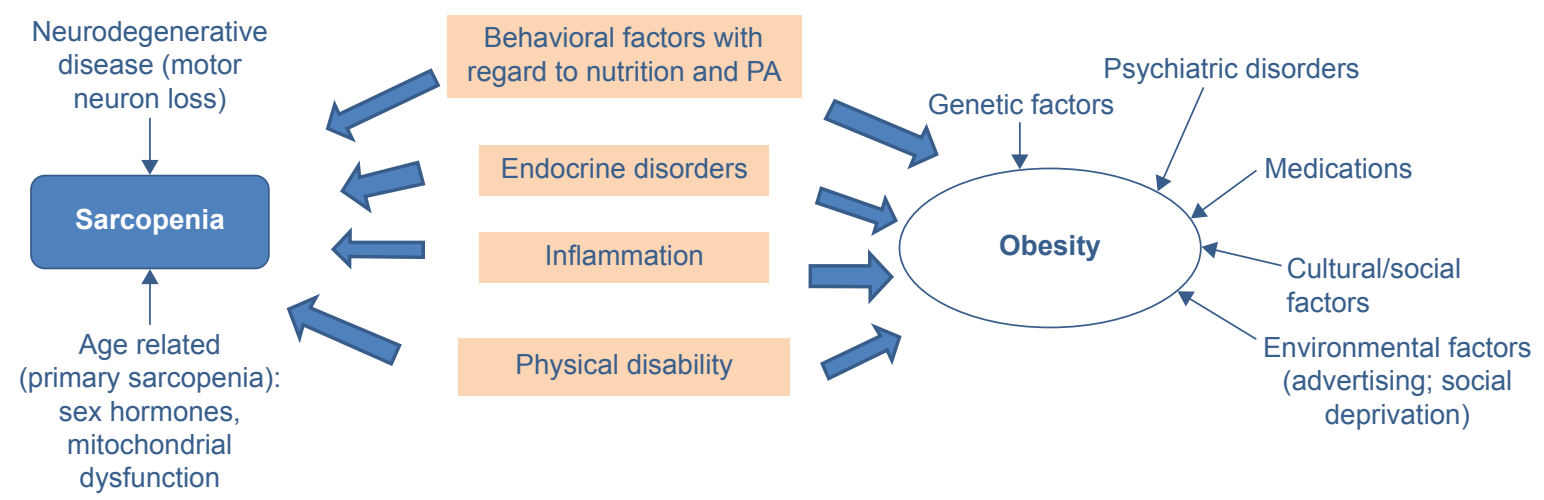

Figure I Contributing factors for sarcopenia and obesity

Abbreviation: PA, physical activity.

illustrates the interaction of both on different factors contributing to SO.

\section{Physical activity}

Several studies have demonstrated reciprocal effects between decline in PA and the loss of muscle mass and muscle quality (either muscle function or strength). ${ }^{50-52}$ This leads to the loss of metabolically active tissue accompanied by a decline in energy expenditure. ${ }^{46}$ Weight gain and obesity occur as a result of the often consequent negative balance between PA and dietary intake. As the visceral fat depots produce proinflammatory adipokines, low-grade inflammation is characteristic for obesity. This has a catabolic effect on muscle mass, ${ }^{24,27,37,45}$ and thus, obese subjects are more susceptible to muscle wasting under energy restriction. Furthermore, with the aging process, lean muscle mass is changed into fatty muscle mass by an infiltration of fat into muscle. ${ }^{27}$ These internal changes again lead to changes in muscle function..$^{29,37,53}$ Since women per se have lower muscle mass and lower muscle strength than men, and tend to have more body fat, they are at greater risk for developing sarcopenia and $\mathrm{SO}^{29}$

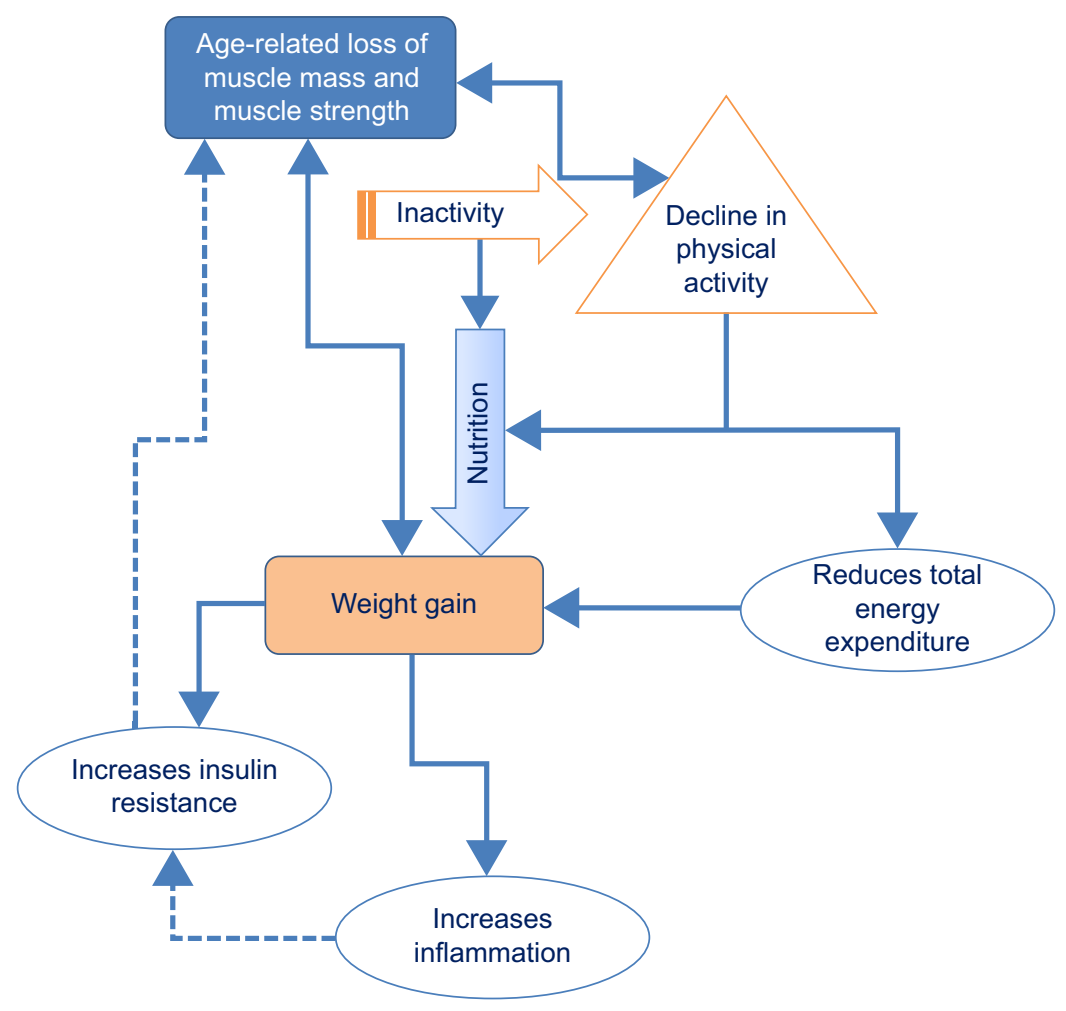

Figure 2 Influences of physical activity and nutrition on sarcopenic obesity. 


\section{Nutrition}

\section{Weight loss diets}

To tackle the health problem SO, two seemingly contradictory approaches have to be taken at the same time: gaining (muscle) mass while losing (fat) mass. Therefore, the effects of any intervention on SO cannot be measured in change of body weight alone, but have to focus on changes in body composition and/or functional parameters.

In addition, "simple" interventions aiming at the management of body weight in older adults are controversial, because any weight loss, whether intentional or not, may have harmful effects by promoting sarcopenia, bone loss, nutritional deficiencies, and even excess mortality in older adults. ${ }^{12,15,20,54-57}$ It is estimated that approximately $25 \%$ of the weight loss achieved with short-term energy-restricted diets is loss of lean muscle mass. ${ }^{15,22,23,37,41,56,58}$ Moreover, research revealed that the prevalent weight regain after weight loss is predominantly a gain in fat mass and not in lean body mass, and thus repeated phases of loss and regain (also called "weight cycling") might produce or exacerbate SO. ${ }^{24,56}$ Therefore, long-term maintenance of the reduced body fat mass and the preserved lean body mass is of utmost importance after any intervention.

An additional aspect in this context is the evidence from several meta-analyses that being overweight up to a BMI of $30 \mathrm{~kg} / \mathrm{m}^{2}$ or more may even protect older persons against mortality and morbidity, and that the harmful effects of obesity only increase at a BMI $>30 \mathrm{~kg} / \mathrm{m}^{2}$ or more. ${ }^{15,16,20,54}$

The previously mentioned aspects imply that weight management in older persons has to be approached with great care and that interventions that work in younger adults should not simply be extrapolated to older populations with low muscle mass and frailty. ${ }^{20,57}$ This is especially the case for diets with very low-energy intake $(<1,000 \mathrm{kcal} / \mathrm{d})$, which are strongly discouraged in the older population. ${ }^{22,56}$ A moderate energy restriction of 200-750 kcal/d, targeted at a moderate weight loss of $0.5-1 \mathrm{~kg} / \mathrm{wk}$ or $8 \%-10 \%$ of initial body weight after 6 months, while assuring a protein intake of at least $1 \mathrm{~g} / \mathrm{kg}$ body weight (BW)/d and appropriate intake of micronutrients, is more advisable and seems to have the most beneficial long-term results in the general population, especially when combined with PA and/or exercise. ${ }^{22,56,59}$ Considering the danger implied by "weight cycling", which might even cause sarcopenia or SO, concepts to support long-term maintenance of the reduced body fat mass including support for permanent dietary changes and PA need to be part of every intervention aimed at treating obesity in older persons. ${ }^{56}$

\section{Protein and essential amino acids}

The nutrients most consistently associated with sarcopenia and $\mathrm{SO}$ are proteins or (essential) amino acids (AAs), ${ }^{46,49,60,61}$ as muscle tissue consists mainly of protein and is the largest reservoir of AAs in the body. An association between inadequate protein intake and worse physical performance in older adults has been shown in epidemiological studies. ${ }^{46}$ The currently recommended dietary allowance for protein to meet the needs of adults is $0.8 \mathrm{~g} / \mathrm{kg} \mathrm{BW} / \mathrm{d},{ }^{62}$ however, this recommendation is increasingly discussed as inadequate to maintain, or help regain, muscle mass in the older population. ${ }^{63-65}$ The AAs absorbed from dietary intake (especially essential AAs) have a stimulatory effect on muscle protein synthesis after feeding, ${ }^{46,61,63,64,66-68}$ and it has been shown that older persons need a higher protein intake to stimulate protein synthesis than younger ones (the so-called "anabolic resistance", reviewed by many authors ${ }^{63,64,68-71}$ ). Recent guidelines and recommendations on nutrition in older persons $s^{64,68,72}$ thus recommend a daily protein intake of $0.8-1.5 \mathrm{~g} / \mathrm{kg} \mathrm{BW} / \mathrm{d}$ for older persons to assure optimal muscle function with aging. For persons already diagnosed with sarcopenia, the protein intake recommendation is at least $1.5 \mathrm{~g} / \mathrm{kg} \mathrm{BW} / \mathrm{d}$, comprising up to $30 \%$ of total daily energy intake. ${ }^{63,73}$ Besides the importance of the overall amount of ingested protein, there is evidence that because of anabolic resistance, older individuals have a higher per-meal protein threshold (ie, 25-30 g of protein per meal), which has to be exceeded at every protein ingestion to promote anabolism. . $33,64,68,69^{-}$

Another aspect of a high-protein diet that could provide a potential benefit in the context of SO is the supposedly greater satiating effect of proteins, which should facilitate compliance with a potentially necessary moderate energyrestriction diet. ${ }^{63}$ However, to what extent this applies to older obese patients, also in the context of the anorexia of aging, remains to be clarified. ${ }^{63}$ Given that a quantitatively adequate supply of protein is assured, increasingly more attention is dedicated to the ideal amount of single essential AA types. ${ }^{74}$ AA availability is controlled mainly by splanchnic tissues (mainly gut and liver), and in aging, an increased first-pass extraction effect by these tissues has been described, limiting the availability of certain AAs (mainly leucine and phenylalanine) for muscle protein synthesis. ${ }^{71,75}$ This increase of extraction is discussed to be even more pronounced in older persons with a higher BMI. ${ }^{76}$ Provision of essential AAs with a high proportion of leucine increased the muscle synthesis rate of older persons. ${ }^{77}$ Leucine has been shown to have a specific regulatory function in the signaling 
pathway controlling muscle protein synthesis in rats, ${ }^{78}$ and has a high potency to release insulin. ${ }^{75}$ Insulin is a potent anabolic stimulus ${ }^{79}$ inhibiting proteolysis, promoting postprandial muscle anabolism and net muscle protein accumulation, and is required for the optimal anabolic stimulation by essential AAs. ${ }^{67}$ The sensitivity of the muscle to anabolic stimuli appears to decrease with aging not only for protein but also for hormones like insulin, ${ }^{66}$ which might contribute to the diminished capacity of essential AAs to stimulate anabolism in older adults. As insulin resistance increases further with increasing (over-) weight and the consequent increase in intramyocellular fat mass, ${ }^{66}$ obesity in older age may well contribute to attenuated muscle anabolism and thus to the development of (sarcopenic) obesity (reviewed in Kob et $\mathrm{al}^{27}$ ).

Currently under debate is whether the source of protein is also a relevant factor. ${ }^{69-71}$ In some studies, high-leucine containing and rapidly digested whey proteins showed an advantage over isolated casein and soy proteins. ${ }^{80}$ However, to date, evidence remains inconclusive. ${ }^{74}$

Additionally, inactivity also seems to induce anabolic resistance in older adults, as shown by decreased response of muscle protein synthesis to protein ingestion and lowered leg muscle mass. ${ }^{27,70,71}$ Accordingly, the effects of protein supplementation on postprandial protein synthesis have been found to be greater when combined with exercise. ${ }^{68,80}$ Current strategies to overcome anabolic resistance in older persons thus include an adequate supply with leucine and other essential AAs in combination with exercise. ${ }^{27,66,69,81}$

\section{Vitamin D}

Vitamin D is another nutrient that has been associated with reduced muscle mass and strength, gait impairments, decreased balance, and increased risk of falls when deficient. ${ }^{24,33,49,60,61,82-86}$ Vitamin D deficiency is reported to be a common problem in older persons. ${ }^{60,73}$ Reduced exposure to sunlight and the decreased capacity of older skin to produce vitamin $\mathrm{D}$ may add to dietary deficiencies. ${ }^{82}$ This results in vitamin $\mathrm{D}$ insufficiency, which can be defined by a 25 -hydroxy(OH)-D level $<75 \mathrm{nmol} / \mathrm{L}$ (=30 ng/L). ${ }^{84}$ In the NHANES study in the US, more than $30 \%$ of adults aged 70 years and older even had vitamin D levels below $50 \mathrm{nmol} / \mathrm{L} .{ }^{83}$ Obesity is also reported to be associated with low vitamin D levels, ${ }^{85}$ and multiple cross-sectional studies in community-dwelling older adults have found a direct association between vitamin D status and parameters of physical performance, especially when 25-OH-D levels are less than $75 \mathrm{nmol} / \mathrm{L} .^{82,85,86}$
Combination of essential amino acids, leucine, and vitamin D Based on the previously mentioned scientific findings, the Society for Sarcopenia, Cachexia and Wasting Disease ${ }^{73}$ recommended for the management of sarcopenia a total protein intake of $1-1.5 \mathrm{~g}$ protein $/ \mathrm{kg} \mathrm{BW} / \mathrm{d}$, a leucine-rich balanced essential AA mix, and an adequate supply with vitamin D, stating that doses up to 50,000 IU/wk are regarded as safe.

\section{Other nutritional supplements}

Other nutritional supplements that have been tested in older adults are creatine, $\beta$-hydroxy- $\beta$-methylbutyrate $(\beta$-HMB, a leucine metabolite), the AA arginine and $\beta$-alanine, omega 3 fatty acids, and a number of antioxidant nutrients including carotenoids, selenium, vitamins $\mathrm{E}$ and $\mathrm{C}$, and isoflavones (reviewed by many authors ${ }^{31,33,46,47,49,60,61,64,65,68,69,86-88}$ ). Creatine is needed in the muscle to provide energy for muscle contraction. ${ }^{87}$ It is mainly synthesized in the human body from several AAs and can additionally be supplied by eating meat and seafood. Like the leucine derivative $\beta-\mathrm{HMB}$, it has long been popular in athletics and bodybuilding to improve performance. For both substances, some smaller interventional studies in older adults suggest that a supplementation as addition to exercise may be beneficial for muscle mass and function, while others found no benefit. ${ }^{64,68,87}$ Overall, the number of studies is too small to draw any conclusions regarding relevant effects of these substances, and the same applies for the use of arginine, $\beta$-alanine, omega 3 fatty acids, or any antioxidants. ${ }^{31,33,47,61,88}$

\section{Current state-of-the-art of interventions in sarcopenic obesity}

Recent statements and reviews on sarcopenia and obesity, but less in SO, have highlighted some possible approaches for effective nonpharmacological interventions through nutrition and exercise. In view of the current scarcity of evidence on interventions successful in counteracting SO, the following section will address the current state-of-the-art for each type of intervention (combined exercise and nutrition interventions, exercise interventions, nutritional interventions [weight management and/or with supplements]) in each single pathway: for SO (including the "frail obese" elderly) as well as for sarcopenia and obesity (focused on the older population) alone.

\section{Sarcopenic obesity}

To the best of our knowledge, there are no studies explicitly addressing older SO populations with combined exercise and nutritional interventions including specific weight loss targets. $^{31,37}$ 
Regarding obese and frail older adults, a group around Villareal et a ${ }^{89}$ could demonstrate positive effects of their complex intervention combining a weight loss diet and exercise on body weight and function (measured with the Physical Performance Test). Participants - communitydwelling obese (BMI $\geq 30 \mathrm{~kg} / \mathrm{m}^{2}$ ) and mild-to-moderately frail adults $\geq 65$ years - completed three 90 -minute supervised ET sessions on 3 nonconsecutive days per week over 52 weeks. The exercise intervention consisted of strength and endurance exercises ( $\sim 30$ minutes each) and, to a lesser extent, of balance and flexibility exercises. In the nutritional intervention, a diet with an energy deficit of 500-750 kcal/d and a protein content of $1 \mathrm{~g} / \mathrm{kg} \mathrm{BW} / \mathrm{d}$ was prescribed, and weight loss was targeted at $10 \%$ of the participant's baseline body weight after 6 months' intervention and an additional 6 months of weight maintenance. Best effects on function were found in the combined weight loss diet and exercise group when compared with a control group without intervention or with exercise alone or weight loss diet alone. Function increased by $21 \%$ from baseline in the combined group, whereas the weight loss diet only group increased by $12 \%$ and the exercise only group by $15 \%$ (control group $1 \%$ increase).

In the area of combined exercise and nutritional interventions with supplements or exercise alone/nutrition alone interventions, to our knowledge, also no research has been performed so far in SO populations. ${ }^{31,37}$

\section{Sarcopenia}

\section{Combined exercise and nutritional interventions}

Interventions with any weight loss targets are, of course, inappropriate for sarcopenic nonobese patients, but several reviews have summarized the evidence on complex interventions combining exercise and nutritional supplementation in older persons with sarcopenia. ${ }^{46,47,64,69,70,74,88,90-94}$

\section{Protein and (essential) amino acids}

Although the evidence is not conclusive, as study populations and designs so far have been very heterogeneous, ${ }^{46,47,88}$ the previously mentioned reviews largely point in the same direction: Regarding the exercise program, many reviews suggested that resistance training together with protein or AA supplementation (mainly in the form of whey or casein protein or mixed/individual AA) provides beneficial effects on muscle function and/or muscle size. ${ }^{47,70,88,90,94}$ Only scant evidence is available at the moment regarding the best timing of supplement intake (directly before or after exercise), the dosage of protein or AA supplements, ${ }^{69,74,94}$ and exercise load.
Another open question is the duration of the intervention and the best exact composition of nutritional supplements. ${ }^{69,74}$ A recent study by Tieland et a ${ }^{81}$ - although addressing frail older persons - demonstrated positive effects on lean muscle mass and strength in a combined intervention of strength training and protein supplementation (15 g protein twice per day) for 24 weeks.

Recently, a study by Daly et al ${ }^{95}$ evaluated a proteinrich diet $(1.3 \mathrm{~g} / \mathrm{kg} \mathrm{BW} / \mathrm{d})$ high in lean meat in combination with resistance training in healthy older people, and found a significant increase in muscle mass and strength, implying that also dietary modifications including protein-dense foods might be a promising approach.

\section{Exercise interventions}

\section{Exercise interventions with strength training}

In the community-dwelling older population, a meta-analysis by Peterson et $\mathrm{al}^{42}$ verified that an average of 20.5 weeks of progressive resistance training increases lean body mass in men and women significantly by $1.1 \mathrm{~kg}$. These findings are consistent with those of Liu et a ${ }^{96}$ namely, that resistance training has a positive effect on muscle function in older persons. In older persons with sarcopenia, progressive resistance training has demonstrated positive effects on muscle size, protein synthesis rate, neuromuscular function, insulin sensitivity, and inflammation. ${ }^{40,97}$ Nevertheless, the doseresponse relationship is not yet clear, and the problem of how to transfer insights from interventions for sarcopenia to $\mathrm{SO}$ in older persons remains. Evidence evolves that muscle power training might have a more pronounced effect on muscle function than strength training. ${ }^{98,99}$ Reviews have summarized the effects of power training on independence in activities of daily living ${ }^{100}$ and on functional performance, ${ }^{98,101}$ and overall, more effect was found if high-velocity power training was included.

\section{Exercise interventions with Whole-Body Vibration and Whole-Body Electromyostimulation}

Although exercise may currently be the most effective tool available to manage sarcopenia in older age, enthusiasm for regular exercise is less prevalent in this vulnerable cohort. ${ }^{102}$ For these subjects, Whole-Body Vibration (WBV) or Whole-Body Electromyostimulation (WB-EMS) training may be an appealing alternative to conventional types of ET as a time-saving option for positively impacting body composition and functional capacity. ${ }^{103}$ While the effect of WBV on musculoskeletal parameters has been frequently addressed and may thus be considered as fairly evident, ${ }^{104,105}$ 
the corresponding impact of WB-EMS is less investigated. Recent studies, however, determined good effects of this exercise technology on muscle mass, (abdominal) body fat, strength, power, and aerobic capacity in older persons at risk for sarcopenia, obesity, or both. ${ }^{106-109}$

\section{Exercise interventions with aerobic exercise}

According to a review by Pillard et $\mathrm{al}^{97}$ another area for addressing sarcopenia could be aerobic exercise. Moderate aerobic exercise has been part of all recommendations for overall PA in older persons. ${ }^{87}$ Aerobic exercise would address the metabolic pathway in older persons with sarcopenia. ${ }^{27}$ Evidence on aerobic exercise targeting sarcopenia in older persons is just developing and will hopefully evolve in the upcoming years.

\section{Complex exercise interventions}

A recent review by Cruz-Jentoft et $\mathrm{al}^{88}$ of studies in mostly community-dwelling frail older persons reported that overall, most studies found an increase in muscle strength and physical performance by different combinations of exercise (aerobic, strength, flexibility and/or balance training), but less evidence of an increase in muscle mass.

\section{Nutritional interventions}

Again, interventions with weight loss targets are, of course, inappropriate, but some research has been performed in the area of "supplementation-only" interventions to attenuate sarcopenia.

\section{Protein and (essential) amino acids}

While epidemiologic studies have shown interesting correlations between the different levels of protein intake and functional outcomes, and thus protein and/or AA supplementation should have the potential to slow sarcopenic muscle loss, interventional studies using such supplements (mainly in the form of whey or casein protein or mixed/individual AA) up to now have only provided heterogeneous results. ${ }^{46,47,49,60,65,74,86,88,110}$ AA supplementation has been shown to increase lean mass and improve physical function in some studies; ${ }^{69,74}$ however, other trials have not been successful. ${ }^{46,47,49,86}$ On the one hand, supplementation of protein or AAs in addition to usual food intake have so far failed to show beneficial effects on strength and performance in malnourished seniors, ${ }^{111}$ while on the other hand, such effects have been found in a meta-analysis mainly including older patients with various diseases. ${ }^{112}$ Recently, Tieland et al ${ }^{113}$ reported that protein supplementation did improve physical performance in a frail community-dwelling population versus a control group even without additional exercise, but rather surprisingly, no corresponding improvement in muscle mass or muscle strength was found.

A recent review and meta-analysis by Komar et $\mathrm{al}^{110}$ analyzed the effects of leucine supplementation, and concluded that it was able to increase body weight and lean body mass in healthy older persons when compared with controls, and had even bigger effects in those with manifest sarcopenia. However, in these mainly short-term interventions (10 days to 6 months), the positive changes once again did not translate into an increase in strength parameters.

However, in the vulnerable population of frail sarcopenic older adults, it might well be that small gains, and even the stabilization of current functional status, should be regarded as a relevant therapeutic achievement from an individual and a public health perspective. ${ }^{69}$ For example, in a trial by Kim and Lee, ${ }^{114}$ frail older persons received energy-protein supplementation over 12 weeks, which reduced functional decline in this population compared with placebo controls.

Here again, the approach with dietary modifications increasing protein intake from regular foods must be taken into consideration. In this area, Aléman-Mateo et $\mathrm{al}^{115}$ found that adding $210 \mathrm{~g}$ of protein-dense ricotta cheese daily to habitual diet in healthy older persons was able to increase muscle mass and preserve muscle strength compared with controls.

\section{Vitamin D}

Regarding the supplementation of vitamin D in order to attenuate sarcopenia, evidence remains inconclusive. ${ }^{33,49,85,86}$ From their systematic review, Annweiler et al ${ }^{116}$ concluded that evidence from studies mostly conducted in communitydwelling older women remained controversial due to the diverging results regarding balance, gait, muscle strength, and function.

Another recent meta-analysis found no effect of vitamin D supplementation in older adults with baseline $25-\mathrm{OH}-\mathrm{D}>25 \mathrm{nmol} / \mathrm{L}$, whereas supplementation increased lower limb muscle strength in vitamin D-deficient (<25 nmol/L 25-OH-D) geriatric inpatients. ${ }^{117}$ Muir and Montero-Odasso ${ }^{118}$ concluded from their meta-analysis that studies with a daily dose of 800 IU or more vitamin $\mathrm{D}$ demonstrated beneficial effects on balance and muscle strength also in older adults with higher 25-OH-D levels, although the magnitude of the effects was small. To date, the huge variations in the characteristics of different study populations, the heterogeneous initial degrees of vitamin $\mathrm{D}$ insufficiency, and doses of vitamin D tested preclude any reliable conclusions. ${ }^{49,85,86}$ 
Combination of essential amino acids, leucine, and vitamin D Recently published results of an interventional randomized controlled trial in older persons with limited mobility showed that bidaily intake of a supplement providing $21 \mathrm{~g}$ protein, $10 \mathrm{~g}$ essential AAs, $3 \mathrm{~g}$ leucine, and $800 \mathrm{IU}$ vitamin D for a period of 12 weeks could significantly improve muscle mass and the results of the chair-stand test. ${ }^{119}$ The study setting did not include any physical training modules. The primary endpoints of this trial (improved results in the Short Physical Performance Battery), however, were not met, indicating that functionality depends on more complex factors (like central nervous steering mechanism) which probably cannot be influenced to a sufficient extent by nutritional supplementation alone.

\section{Obesity}

\section{Combined exercise and nutritional interventions}

As already mentioned, energy-restricted diets without ET and possibly complementary dietary modifications (increase of protein intake, dietary counseling) are inadvisable, as they provoke loss of lean muscle mass. ${ }^{15,56}$ Several reviews that have analyzed the effects of combined weight loss diet and exercise interventions in obese older adults in the last years $^{16,41,57,120-123}$ found that there is still a lack of studies specifically aimed at older adults, and, moreover, that current research is mainly focused on cardiovascular risks and not on functional aspects. ${ }^{15}$

A systematic review by Weinheimer et $\mathrm{al}^{41}$ on the separate and combined effects of energy restriction and exercise on fat-free mass in middle-aged and older adults showed that the addition of exercise to energy restriction clearly attenuated the loss of fat-free mass, and was more effective for weight loss than exercise only. McTigue et al ${ }^{122}$ concluded that counseling-based interventions incorporating low-calorie diets in combination with moderate PA and exercise in the older obese led to modest (3-4 kg) but sustained weight loss that was sufficient to improve metabolic symptoms (ie, glucose control, elevated blood pressure). Witham and Avenell, ${ }^{121}$ in their systematic review and meta-analysis, reported that such combined interventions had modest effects on body weight that were greater than those of diet-only interventions. However, these changes in body weight did not translate into improvements in cardiovascular risk factors or in glycemic control.

A recent review by Miller et $\mathrm{l}^{120}$ dealt with the effects of exercise additional to energy restriction compared with energy restriction alone, including studies from all age groups. In the studies with older populations, additional exercise provided benefits regarding cardiovascular risk factors, lean mass preservation, and muscle strength compared with energy restriction alone. ${ }^{120} \mathrm{~A}$ review by Rejeski et al ${ }^{16}$ also provided information on this topic, although here most data are related to the specific target group of knee osteoarthritis patients. In these patients, a combination of intentional weight loss induced by energy restriction and aerobic/strength training had positive effects on various functional parameters as well as on self-reported self-efficacy. ${ }^{16}$

The American College of Sports Medicine ${ }^{124}$ also clearly stated that independent of age, a combination of PA (preferably aerobic exercise) and energy restriction is the most appropriate approach to reduce obesity. The recommendation also states that there is a dose-response relationship between the amount of PA and weight loss or change in body composition. ${ }^{124,125}$ Approximately 150 minutes of aerobic exercise per week resulted in a modest weight loss of approximately $2-3 \mathrm{~kg}$, whereas PA $>225-420 \mathrm{~min} / \mathrm{wk}$ resulted in 5-7 kg weight loss. ${ }^{124} \mathrm{PA}$ is also an important factor in controlling and maintaining weight after weight loss. ${ }^{124,126}$ This recommendation was recently backed by a systematic review and meta-analysis on long-term (12-72 months) lifestyle programs for overweight and obese persons including 21 studies with altogether over 3,500 participants from all ages, ${ }^{127}$ which concluded that combined nutrition and exercise interventions resulted in a greater reduction of body weight and fat mass and bigger improvements in cardiovascular risk factors than interventions with only exercise or nutrition.

To the best of our knowledge, so far no studies have been performed combining exercise and nutritional interventions with supplements in obese older persons.

\section{Exercise interventions}

The influence of exercise or PA on body weight has been addressed in a recent review by Swift et al ${ }^{126}$ although in most studies they reviewed, the target population was obese or adipose adults of all ages, not just older persons. As an overall result, it was demonstrated that with a low overall volume of aerobic ET, no clinically significant weight loss would occur. Only high aerobic training volume produced clinically significant weight loss in the group as a whole, while on an individual level, the weight loss was very heterogeneous. Bocalini et al ${ }^{128}$ investigated a strength exercise intervention in normal weight, overweight, and obese older women. Comparing the control group (no exercise) to groups with exercising normal weight, overweight, and obese persons, respectively, only the obese group showed a significant increase in lean muscle mass. A limitation of this study is 
the small number of subjects in each group, ranging from 9 to 18 participants.

\section{Nutritional interventions}

Taking into account the risk of weight loss diets generating or exacerbating SO in older adults, as has been discussed earlier, it is no surprise that such intervention trials in older persons with obesity are rather rare. Some energy restriction-only interventions have shown positive effects for weight loss when compared with exercise alone groups or controls, and these effects had the same magnitude as the effects of combined weight loss diet and exercise interventions. ${ }^{41}$ However, the addition of exercise to energy restriction resulted in an attenuated loss of muscle mass, which is of utmost importance in older cohorts. A meta-analysis of Wycherley et al ${ }^{129}$ that compared higher protein (1-1.6 g/kg BW/d, 27\%-35\% of daily energy intake) with standard protein $(0.5-0.9 \mathrm{~g} / \mathrm{kg} / \mathrm{d}$, $16 \%-21 \%$ of daily energy intake) low-fat energy-restriction diets in 24 studies comprising all age groups concluded that the higher protein diets led to greater weight loss and fat loss than the standard protein diets, and the higher protein diets were also associated with greater lean mass retention during energy restriction.

Again, to our knowledge, no nutritional interventions with addition of supplements have been performed in older persons with obesity. ${ }^{31}$

\section{Discussion}

To date, several complex interventions with different outcomes have been conducted and have shown promising results in counteracting either sarcopenia or obesity, but only a few studies have addressed the complex syndrome of SO with the earlier discussed approaches (exercise, weight management, nutritional supplements), thus making it hard to give recommendations to counteract $\mathrm{SO}$ at this time. Table 1 summarizes the findings of this review and shows gaps in present knowledge.

Complex exercise interventions containing different elements (eg, strength, aerobic, flexibility, and balance) for older persons with SO are still rare. With regard to stand-alone single exercise-type interventions, up to now power training has not been conducted in this target group. Starting an intervention with a strength training protocol and moving on to power training during the training period might be an interesting way to address neuromuscular function.

For sarcopenia, the most robust evidence exists for strength training. For supplementation with protein or AA in sarcopenic patients, to date there are indicative results but not solid proof for beneficial effects. ${ }^{88}$

For obese older persons, research has demonstrated only minor weight loss effects (up to $2 \mathrm{~kg}$ ) with aerobic exercise only, ${ }^{126}$ whereas strength exercise in combination with a dietary weight loss intervention demonstrated positive effects on muscle function and a significant reduction of body fat. ${ }^{130}$

Still, in older adults, weight management has to be approached with great care, and weight loss diets with very low-energy intake $(<1,000 \mathrm{kcal} / \mathrm{d})$ are strongly discouraged. ${ }^{22,56}$ Also, the treatment of SO with energyrestricted diets without the synergistic effects of ET and complementary dietary modifications (increase of protein intake, nutritional counseling) is inadvisable, as this might exacerbate loss of lean muscle mass in these patients and generally seems to be less effective than a combined approach. ${ }^{15,20,37,56}$ As already mentioned, moderate energy restriction of $500-750 \mathrm{kcal} / \mathrm{d}$, targeted at a weight loss of $0.5-1 \mathrm{~kg} / \mathrm{wk}$ or $8 \%-10 \%$ of initial body weight after 6 months, and even more moderate (starting from $200 \mathrm{kcal} / \mathrm{d}$ ) for already sarcopenic obese older persons, while assuring a protein intake of at least $1 \mathrm{~g} / \mathrm{kg} \mathrm{BW} / \mathrm{d}$ and appropriate intake of micronutrients is recommended. ${ }^{22,56,59}$ Yet, an additive effect of high protein intake on lean mass preservation during periods of energy restriction and training still remains to be clearly proven for older adults. ${ }^{56}$

Generally, any weight loss diets should be considered only for clearly obese (at least BMI $>30 \mathrm{~kg} / \mathrm{m}^{2}$, and some propose even a BMI $>35 \mathrm{~kg} / \mathrm{m}^{2}$ ) older persons presenting with risk factors for obesity-related adverse health effects and mobility limitations, where beneficial effects of a moderate reduction of body fat mass are expectable,,$^{12,20,22,54,59}$ as it is not yet clearly established that weight loss generally improves physical function. ${ }^{16}$ Moreover, in the context of the "obesity paradox", where several meta-analyses indicate that being overweight up to a BMI of $30 \mathrm{~kg} / \mathrm{m}^{2}$ or even more may even protect older persons against mortality and morbidity and that the harmful effects of obesity only increase at a $\mathrm{BMI}>30 \mathrm{~kg} / \mathrm{m}^{2}$ or more, ${ }^{15,20,54}$ the necessity of weight loss treatments has to be thoroughly reflected for every individual. A thorough medical examination evaluating possible risks and benefits of the intervention and reviewing the medication for potentially weight-increasing drugs is thus always necessary before starting any weight reduction regimen. It is also of utmost importance to integrate long-term PA concepts for weight maintenance with preservation of lean mass in order to avoid the deleterious effects of weight cycling in these patients. ${ }^{22,56,59}$ 
Table I Evidence on interventions in sarcopenic obesity

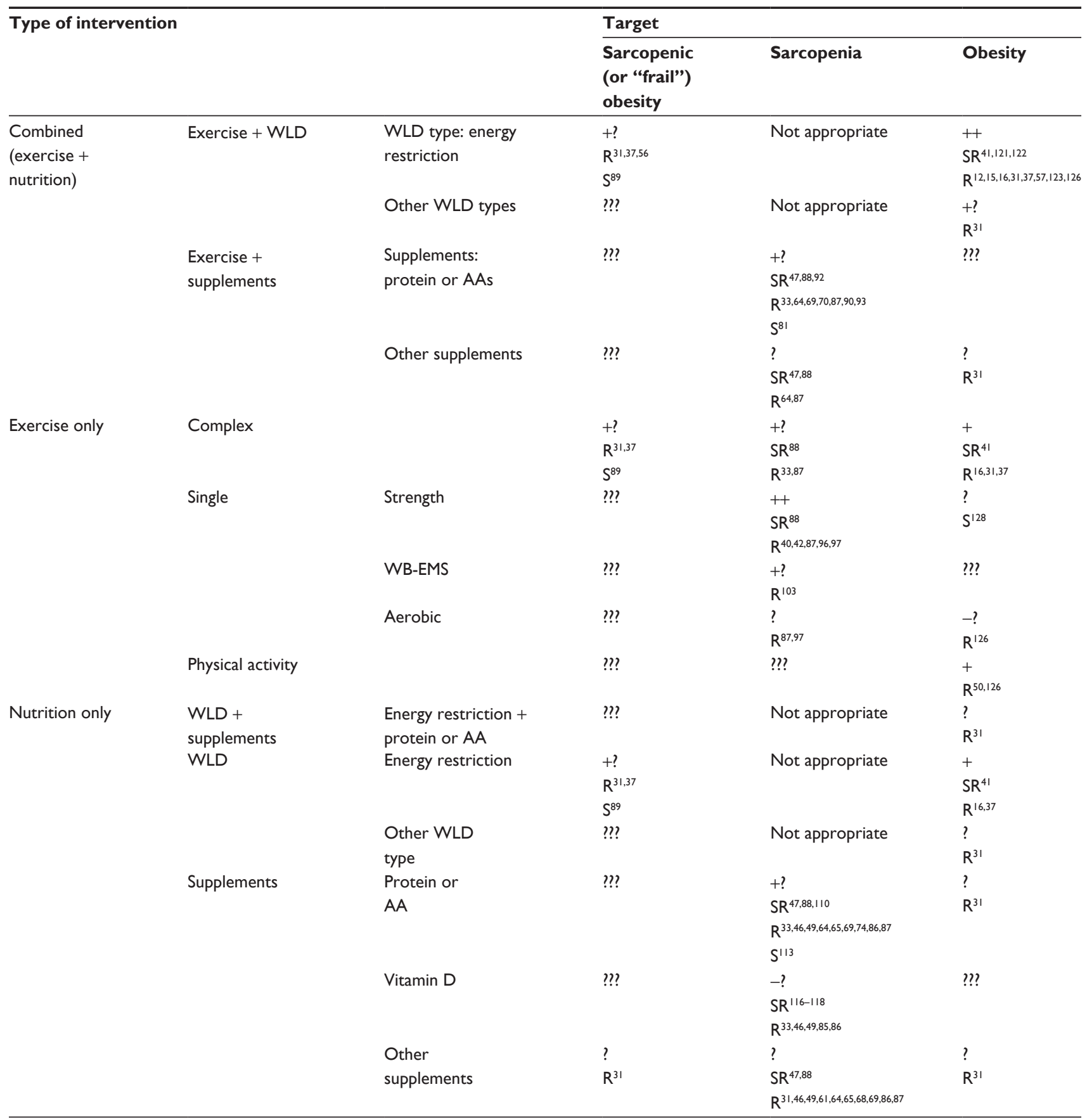

Notes: ++, good evidence on effects; +, some evidence on effects; -, no effects; ?, more evidence needed; ??, no evidence found.

Abbreviations: SR, systematic review; R, review; S, single study; WLD, weight loss diet; AA, amino acid; WB-EMS, whole-body electromyostimulation.

Furthermore, in previous studies, only combined interventions with a duration of longer than 3 months and being provided at least 2 days a week (or more) resulted in relevant improvement in physical function compared with weight loss diet or exercise alone. ${ }^{130,131}$

For further development of the current state-of-the-art in SO treatment, more studies that specifically include only older subjects are needed. With regard to the most appropriate target group for effective interventions in $\mathrm{SO}$ and $\mathrm{SO}$ prevention, such complex interventions preferably should address older women, since women per se have lower muscle mass and lower muscle strength than men. ${ }^{17}$ Additionally, they are at greater risk for developing $\mathrm{SO}$, as the rate of change of fatfree muscle mass to fat muscle mass that accompanies weight gain is more pronounced in women than in men. ${ }^{29}$ Moreover, at the moment, women represent the majority in the older 
population, and from a demographic point of view, women live longer and suffer from a greater burden of disability. ${ }^{132}$

The establishment of a reasonable and widely accepted definition of SO and clear cutoff values is an essential prerequisite for advancing research in this area, and the same applies for sarcopenia and obesity requiring treatment in older persons.

Future interventions should investigate the optimal amount of weight loss with respect to maintenance of lean muscle mass, while preferably always using body composition and functional parameters as outcome measures. The effectivity of any intervention for SO should then be judged according to its capability to lower fat mass while maintaining or increasing lean mass, and, most important, functionality.

There is a need to examine the effects of either strength, power, or a combination of both exercise modes, and the role of nutritional supplements should be investigated with regard to muscle quality and function..$^{22,88,126,130}$ Also, adequate follow-up time is needed to be able to assess the long-term health consequences of such interventions. ${ }^{133}$ Additionally, the topic of adherence should be addressed, because no data are available on relapses or longitudinal compliance with implemented programs.

To the best of our knowledge, only little research has been conducted so far to investigate the motivational and cognitive aspects of older participants in a scientific intervention study. Also, "fear of falling" has never been thoroughly investigated in this cohort. Fear of falling can fuel a negative spiral by reducing $\mathrm{PA}$ in order to reduce the risk of falling, thus entering the circle described in Figure 2. ${ }^{134-136}$ Effective complex interventions will not reach the target SO population if they stay at home or reduce their daily PA due to fear of falling. Only Vincent et al ${ }^{130}$ have recognized the symptom of fear of movement in obesity research, describing the negative influence of pain on the motivation for exercise but increasing avoidance of PA.

Another important aspect very rarely addressed so far in sarcopenia, obesity, or SO research is the influence of selfefficacy. An older person with either sarcopenia or obesity or SO might not be easily integrated into a group-based exercise program due to lack of self-efficacy. As research has demonstrated in behavioral change interventions, the aspect of self-efficacy is an important factor, very often deciding about compliance and adherence. ${ }^{137,138}$ Therefore, exercise programs should start at a lower intensity or with a less demanding protocol to motivate and secure older sarcopenic obese participants, thus increasing compliance and adherence. ${ }^{137,138}$ The WB-EMS technique could be such an innovative low-level approach to start an exercise program for this target group. Depending on gain in muscle function and quality, the participants can progress to other groupbased exercise programs later on.

\section{Limitations}

The limitations of this narrative review stem from the general lack of high-quality studies with clearly defined study populations and outcomes, the differences in exercise and nutritional intervention modes and study duration, as well as different target populations and the inconsistencies of used terms and definitions, thus making it hard to compare the results of different studies. ${ }^{24}$ Furthermore, it is impossible to extract data for a meta-analysis or give stateof-the-art recommendations based on reliable evidence. So far, only deductive conclusions on the probably best proceeding can be drawn by the existing expertise from different studies.

\section{Conclusion}

In view of the high risk of adverse health outcomes, it is important to counteract $\mathrm{SO}$, and effective interventions are needed. A widely accepted definition of SO and cutoff values for its diagnosis are an essential prerequisite for advancing research in this area. Solid evidence to recommend specific interventions has yet to be established. From what information is available at the moment, the most promising approach should be to conduct randomized controlled studies that contain exercise programs comprising strength and aerobic exercise in combination with dietary interventions that include a supervised moderate weight loss program and/or protein supplementation. However, whether there are clear positive effects on function and quality of life in sarcopenic obese older persons remains to be proven. Future research should also consider that in the vulnerable population of frail sarcopenic older adults, it might well be that any small gain, and even the stabilization of current functional status, can already be regarded as a relevant and clinically important achievement for the individual as well as from a public health perspective.

\section{Acknowledgments}

The authors would like to thank the Bayerische Forschungsstiftung, which supports the working group within the research association "Amyotrophia (Sarcopenia) and Osteoporosis Consequence of limited regeneration in age (FORMOsA)". The FORMOsA project is financially supported by Nutricia $\mathrm{GmbH}$, Danone Medical Nutrition. 


\section{Author contributions}

Ellen Freiberger and Sabine Goisser drafted and wrote the manuscript. Wolfgang Kemmler provided parts of the manuscript (exercise WB-EMS part). Simone Porzel provided parts of the manuscript (nutrition part). Dorothee Volkert contributed to manuscript preparation and revision (nutrition part). Cornel Christian Sieber contributed to manuscript preparation and revision (sarcopenia part). Leo Cornelius Bollheimer contributed to manuscript preparation and revision. All authors contributed toward data analysis, drafting and revising the paper and agree to be accountable for all aspects of the work.

\section{Disclosure}

$\mathrm{S}$ Porzel is an employee of Nutricia GmbH. The authors report no other conflicts of interest in this work.

\section{References}

1. Cruz-Jentoft A, Baeyens JP, Bauer JM, et al. Sarcopenia: European consensus on definition and diagnosis: report of the European Working Group on Sarcopenia in Older People. Age Ageing. 2010;39(4):412-423.

2. Cederholm TE, Bauer JM, Boirie Y, Schneider SM, Sieber CC, Rolland Y. Toward a definition of sarcopenia. Clin Geriatr Med. 2011;27(3): 341-353.

3. Fielding RA, Vellas B, Evans WJ, et al. Sarcopenia: an undiagnosed condition in older adults. Current consensus definition: prevalence, etiology, and consequences. International working group on sarcopenia J Am Med Dir Assoc. 2011;12(4):249-256.

4. Goodpaster BH, Carlson CL, Visser M, et al. Attenuation of skeletal muscle and strength in the elderly: the Health ABC Study. J Appl Physiol. 2001;90(6):2157-2165.

5. Masanes F, Culla A, Navarro-Gonzalez M, et al. Prevalence of sarcopenia in healthy community-dwelling elderly in an urban area of Barcelona (Spain). J Nutr Health Aging. 2012;16(2):184-187.

6. Amigues I, Schott AM, Amine M, et al. Low skeletal muscle mass and risk of functional decline in elderly community-dwelling women: the prospective EPIDOS study. J Am Med Dir Assoc. 2013;14(5):352-357.

7. Janssen I, Shepard DS, Katzmarzyk PT, Roubenoff R. The healthcare costs of sarcopenia in the United States. J Am Geriatr Soc. 2004;52(1): 80-85.

8. Baumgartner RN, Wayne SJ, Waters DL, Janssen I, Gallagher D, Morley JE. Sarcopenic obesity predicts instrumental activities of daily living disability in the elderly. Obes Res. 2004;12(12):1995-2004.

9. Janssen I. Influence of sarcopenia on the development of physical disability: the Cardiovascular Health Study. J Am Geriatr Soc. 2006;54(1): 56-62.

10. Haslam D. Understanding obesity in the older person: prevalence and risk factors. Br J Community Nur. 2008;13(3):115-116, 118, 120-112.

11. Rolland Y, Lauwers-Cances V, Cristini C, et al. Difficulties with physical function associated with obesity, sarcopenia, and sarcopenic-obesity in community-dwelling elderly women: the EPIDOS (EPIDemiologie de l'OSteoporose) Study. Am J Clin Nutr. 2009;89(6):1895-1900.

12. Han TS, Tajar A, Lean ME. Obesity and weight management in the elderly. Br Med Bull. 2011;97:169-196.

13. Himes CL, Reynolds SL. Effect of obesity on falls, injury, and disability. J Am Geriatr Soc. 2012;60(1):124-129.

14. Houston DK, Ding J, Nicklas BJ, et al. Overweight and obesity over the adult life course and incident mobility limitation in older adults: the health, aging and body composition study. Am JEpidemiol. 2009;169(8): 927-936.
15. Mathus-Vliegen EM. Obesity and the elderly. J Clin Gastroenterol. 2012;46(7):533-544.

16. Rejeski WJ, Marsh AP, Chmelo E, Rejeski JJ. Obesity, intentional weight loss and physical disability in older adults. Obes Rev. 2010;11(9): 671-685.

17. Stenholm S, Harris TB, Rantanen T, Visser M, Kritchevsky SB, Ferrucci L. Sarcopenic obesity: definition, cause and consequences. Curr Opin Clin Nutr Metab Care. 2008;11(6):693-700.

18. Dorner TE, Rieder A. Obesity paradox in elderly patients with cardiovascular diseases. Int J Cardiol. 2012;155(1):56-65.

19. Banack HR, Kaufman JS. The obesity paradox: understanding the effect of obesity on mortality among individuals with cardiovascular disease. Prev Med. 2014;62:96-102.

20. Cetin DC, Nasr G. Obesity in the elderly: more complicated than you think. Cleve Clin J Med. 2014;81(1):51-61.

21. Al Snih S, Ottenbacher KJ, Markides KS, Kuo YF, Eschbach K, Goodwin JS. The effect of obesity on disability vs mortality in older Americans. Arch Intern Med. 2007;167(8):774-780.

22. Villareal DT, Apovian CM, Kushner RF, et al. Obesity in older adults: technical review and position statement of the American Society for Nutrition and NAASO, The Obesity Society. Obes Res. 2005;13(11): 1849-1863.

23. Bouchonville MF, Villareal DT. Sarcopenic obesity: how do we treat it? Curr Opin Endocrinol Diabetes Obes. 2013;20(5):412-419.

24. Prado CM, Wells JC, Smith SR, Stephan BC, Siervo M. Sarcopenic obesity: a critical appraisal of the current evidence. Clin Nutr. 2012;31(5): 583-601.

25. Prado CM, Siervo M, Mire E, et al. A population-based approach to define body-composition phenotypes. Am J Clin Nutr. 2014;99(6): 1369-1377.

26. Batsis JA, Mackenzie TA, Barre LK, Lopez-Jimenez F, Bartels SJ. Sarcopenia, sarcopenic obesity and mortality in older adults: results from the National Health and Nutrition Examination Survey III. Eur J Clin Nutr. 2014;68(9):1001-1007.

27. Kob R, Bollheimer LC, Bertsch T, et al. Sarcopenic obesity: molecular clues to a better understanding of its pathogenesis? Biogerontology. 2015;16(1):15-29. doi:10.1007/s10522-014-9539-7.

28. Atkins JL, Whincup PH, Morris RW, Lennon LT, Papacosta O, Wannamethee SG. Sarcopenic obesity and risk of cardiovascular disease and mortality: a population-based cohort study of older men. J Am Geriatr Soc. 2014;62(2):253-260.

29. Batsis JA, Barre LK, Mackenzie TA, et al. Variation in the prevalence of sarcopenia and sarcopenic obesity in older adults associated with different research definitions: dual-energy X-ray absorptiometry data from the National Health and Nutrition Examination Survey 1999-2004. J Am Geriatr Soc. 2013;61(6):974-980.

30. WHO. Obesity: Preventing and Managing the Global Epidemic. Report of a WHO Consultation. Geneva, Switzerland: WHO; 2000.

31. Poggiogalle E, Migliaccio S, Lenzi A, Donini LM. Treatment of body composition changes in obese and overweight older adults: insight into the phenotype of sarcopenic obesity. Endocrine. 2014;47(3): 699-716.

32. Rosenberg IH. Sarcopenia: origins and clinical relevance. J Nutr. 1997;127(5 Suppl):990S-991S

33. Burton LA, Sumukadas D. Optimal management of sarcopenia. Clin Interv Aging. 2010;5:217-228.

34. Cederholm T, Morley JE. Sarcopenia: the new definitions. Curr Opin Clin Nutr Metab Care. 2014:18(1):1-4. doi:10.1097/MCO.0000000000000119.

35. Dam TT, Peters KW, Fragala M, et al. An evidence-based comparison of operational criteria for the presence of sarcopenia. J Gerontol A Biol Sci Med Sci. 2014;69(5):584-590.

36. Marini E, Buffa R, Saragat B, et al. The potential of classic and specific bioelectrical impedance vector analysis for the assessment of sarcopenia and sarcopenic obesity. Clin Interv Aging. 2012;7:585-591.

37. Porter Starr KN, McDonald SR, Bales CW. Obesity and physical frailty in older adults: a scoping review of lifestyle intervention trials. $J \mathrm{Am}$ Med Dir Assoc. 2014;15(4):240-250. 
38. Caspersen CJ, Powell KE, Christenson GM. Physical activity, exercise, and physical fitness: definitions and distinctions of health-related research. Public Health Rep. 1985;100(2):126-131.

39. WHO. Global Recommendations on Physical Activity for Health. Geneva, Switzerland: WHO Press; 2010.

40. Montero-Fernandez N, Serra-Rexach JA. Role of exercise on sarcopenia in the elderly. Eur J Phys Rehabil Med. 2013;49(1):131-143.

41. Weinheimer EM, Sands LP, Campbell WW. A systematic review of the separate and combined effects of energy restriction and exercise on fatfree mass in middle-aged and older adults: implications for sarcopenic obesity. Nutr Rev. 2010;68(7):375-388.

42. Peterson MD, Sen A, Gordon PM. Influence of resistance exercise on lean body mass in aging adults: a meta-analysis. Med Sci Sports Exerc. 2011;43(2):249-258.

43. Craig P, Dieppe P, Macintyre S, Michie S, Nazareth I, Petticrew M. Developing and evaluating complex interventions: the new Medical Research Council guidance. BMJ. 2008;337:a1655.

44. Tinetti ME, Mendes de Leon CF, Doucette JT, Baker DI. Fear of falling and fall-related efficacy in relationship to functioning among communityliving elders. J Gerontol Med Sci. 1994;49(3):M140-M147.

45. Biolo G, Cederholm T, Muscaritoli M. Muscle contractile and metabolic dysfunction is a common feature of sarcopenia of aging and chronic diseases: from sarcopenic obesity to cachexia. Clin Nutr. 2014;33(5):737-748.

46. Welch AA. Nutritional influences on age-related skeletal muscle loss. Proc Nutr Soc. 2014;73(1):16-33.

47. Malafarina V, Uriz-Otano F, Iniesta R, Gil-Guerrero L. Effectiveness of nutritional supplementation on muscle mass in treatment of sarcopenia in old age: a systematic review. J Am Geriatr Soc. 2013;14(1):10-17.

48. Malafarina V, Úriz-Otano F, Iniesta R, Gil-Guerrero L. Sarcopenia in the elderly: diagnosis, physiopathology and treatment. Maturitas. 2012;71(2):109-114.

49. Millward DJ. Nutrition and sarcopenia: evidence for an interaction. Proc Nutr Soc. 2012;71(4):566-575.

50. Bann D, Kuh D, Wills AK, Adams J, Brage S, Cooper R. Physical activity across adulthood in relation to fat and lean body mass in early old age: findings from the Medical Research Council National Survey of Health and Development, 1946-2010. Am J Epidemiol. 2014;179(10):1197-1207.

51. Gianoudis J, Bailey CA, Daly RM. Associations between sedentary behaviour and body composition, muscle function and sarcopenia in community-dwelling older adults. Osteoporosis Int. 2015;26(2):571-579.

52. Speakman JR, Westerterp KR. Associations between energy demands, physical activity, and body composition in adult humans between 18 and 96 y of age. Am J Clin Nutr. 2010;92(4):826-834.

53. Cooper JA, Manini TM, Paton CM, et al. Longitudinal change in energy expenditure and effects on energy requirements of the elderly. Nutr J. 2013;12(1):73.

54. Darmon P. Intentional weight loss in older adults: useful or wasting disease generating strategy? Curr Opin Clin Nutr Metab Care. 2013;16(3):284-289.

55. Fitzpatrick AL, Kuller LH, Lopez OL, et al. Midlife and late-life obesity and the risk of dementia: cardiovascular health study. Arch Neurol. 2009;66(3):336-342.

56. Parr EB, Coffey VG, Hawley JA. 'Sarcobesity': a metabolic conundrum. Maturitas. 2013;74(2):109-113.

57. Waters DL, Ward AL, Villareal DT. Weight loss in obese adults 65years and older: a review of the controversy. Exp Gerontol. 2013;48(10): 1054-1061.

58. Kohara K. Sarcopenic obesity in aging population: current status and future directions for research. Endocrine. 2013;45(1):15-25.

59. Mathus-Vliegen EM. Prevalence, pathophysiology, health consequences and treatment options of obesity in the elderly: a guideline. Obes Facts. 2012;5(3):460-483.

60. Volkert D. The role of nutrition in the prevention of sarcopenia. Wien Med Wochenschr. 2011;161(17-18):409-415.

61. Robinson S, Cooper C, Aihie Sayer A. Nutrition and sarcopenia: a review of the evidence and implications for preventive strategies. J Aging Res. 2012;2012:510801.
62. WHO. Protein and Amino Acid Requirements in Human Nutrition. WHO Technical Report Series. Geneva, Switzerland: WHO; 2007.

63. Paddon-Jones D, Leidy H. Dietary protein and muscle in older persons. Curr Opin Clin Nutr Metab Care. 2014;17(1):5-11.

64. Bauer J, Biolo G, Cederholm T, et al. Evidence-based recommendations for optimal dietary protein intake in older people: a position paper from the PROT-AGE Study Group. J Am Med Dir Assoc. 2013;14(8):542-559.

65. Beasley JM, Shikany JM, Thomson CA. The role of dietary protein intake in the prevention of sarcopenia of aging. Nutr Clin Pract. 2013; 28(6):684-690.

66. Boirie Y. Physiopathological mechanism of sarcopenia. J Nutr Health Aging. 2009;13(8):717-723.

67. Dillon EL. Nutritionally essential amino acids and metabolic signaling in aging. Amino Acids. 2013;45(3):431-441.

68. Deutz NE, Bauer JM, Barazzoni, et al. Protein intake and exercise for optimal muscle function with aging: recommendations from the ESPEN Expert Group. Clin Nutr. 2014;33(6):929-936.

69. Bauer JM, Diekmann R. Protein supplementation with aging. Curr Opin Clin Nutr Metab Care. 2015;18(1):24-31. doi:10.1097/ MCO.0000000000000124.

70. Dideriksen K, Reitelseder S, Holm L. Influence of amino acids, dietary protein, and physical activity on muscle mass development in humans. Nutrients. 2013;5(3):852-876.

71. Boirie Y, Morio B, Caumon E, Cano NJ. Nutrition and protein energy homeostasis in elderly. Mech Ageing Dev. 2014;136-137:76-84.

72. Volkert D, Bauer JM, Frühwald T, et al. Leitlinie der Deutschen Gesellschaft für Ernährungsmedizin (DGEM) in Zusammenarbeit mit der GESKES, der AKE und der DGG: Klinische Ernährung in der Geriatrie. Teil des laufenden S3-Leitlinienprojekts Klinische Ernährung. Aktuel Ernahrungsmed. 2013;38:e31-e48.

73. Morley JE, Argiles JM, Evans WJ, et al. Nutritional recommendations for the management of sarcopenia. J Am Med Dir Assoc. 2010;11(6): 391-396.

74. Fukagawa NK. Protein and amino acid supplementation in older humans. Amino Acids. 2013;44(6):1493-1509.

75. Jonker R, Engelen MP, Deutz NE. Role of specific dietary amino acids in clinical conditions. Br J Nutr. 2012;108(Suppl 2):S139-S148.

76. Boirie Y, Gachon P, Beaufrere B. Splanchnic and whole-body leucine kinetics in young and elderly men. Am J Clin Nutr. 1997;65(2):489-495.

77. Dangin M, Guillet C, Garcia-Rodenas C, et al. The rate of protein digestion affects protein gain differently during aging in humans. J Physiol. 2003;549(Pt 2):635-644.

78. Kimball SR, Jefferson LS. Regulation of protein synthesis by branchedchain amino acids. Curr Opin Clin Nutr Metab Care. 2001;4(1): $39-43$.

79. Fujita S, Volpi E. Amino acids and muscle loss with aging. J Nutr. 2006;136(1):277s-280s.

80. Pennings B, Boirie Y, Senden JM, Gijsen AP, Kuipers H, van Loon LJ. Whey protein stimulates postprandial muscle protein accretion more effectively than do casein and casein hydrolysate in older men. Am J Clin Nutr. 2011;93(5):997-1005.

81. Tieland M, Dirks ML, van der Zwaluw N, et al. Protein supplementation increases muscle mass gain during prolonged resistance-type exercise training in frail elderly people: a randomized, double-blind, placebocontrolled trial. J Am Med Dir Assoc. 2012;13(8):713-719.

82. Ceglia L. Vitamin D and its role in skeletal muscle. Curr Opin Clin Nutr Metab Care. 2009;12(6):628-633.

83. HoustonDK, ToozeJA,Hausman DB, etal. Change in 25 -hydroxyvitamin D nd physical performance in older adults. J Gerontol A Biol Sci Med Sci. 2011;66(4):430-436.

84. Bischoff-Ferrari H. Vitamin D: what is an adequate vitamin D level and how much supplementation is necessary? Best Pract Res Clin Rheumatol. 2009;23(6):789-795.

85. Cipriani C, Pepe J, Piemonte S, Colangelo L, Cilli M, Minisola S. Vitamin D and its relationship with obesity and muscle. Int J Endocrinol. 2014;2014:841248. 
86. Mithal A, Bonjour JP, Boonen S, et al. Impact of nutrition on muscle mass, strength, and performance in older adults. Osteoporosis Int. 2013;24(5):1555-1566.

87. Forbes SC, Little JP, Candow DG. Exercise and nutritional interventions for improving aging muscle health. Endocrine. 2012;42(1): 29-38.

88. Cruz-Jentoft AJ, Landi F, Schneider SM, et al. Prevalence of and interventions for sarcopenia in ageing adults: a systematic review. Report of the International Sarcopenia Initiative (EWGSOP and IWGS). Age Ageing. 2014;43(6):748-759.

89. Villareal DT, Chode S, Parimi N, et al. Weight loss, exercise, or both and physical function in obese older adults. $N$ Engl J Med. 2011;364(13): 1218-1229.

90. Breen L, Stewart CE, Onambélé GL. Functional benefits of combined resistance training with nutritional interventions in older adults: a review. Geriatr Gerontol Int. 2007;7(4):326-340.

91. Campbell WW, Leidy HJ. Dietary protein and resistance training effects on muscle and body composition in older persons. J Am Nutr. 2007;26(6):696S-703S.

92. Cermak NM, Res PT, de Groot LC, Saris WH, van Loon LJ. Protein supplementation augments the adaptive response of skeletal muscle to resistance-type exercise training: a meta-analysis. Am J Clin Nutr. 2012;96(6):1454-1464.

93. Evans WJ. Protein nutrition, exercise and aging. J Am Nutr. 2004; 23(6 Suppl):601S-609S

94. Pedersen AN, Cederholm T. Health effects of protein intake in healthy elderly populations: a systematic literature review. Food Nutr Res. 2014;58:23364.

95. Daly RM, Rosengren BE, Alwis G, Ahlborg HG, Sernbo I, Karlsson MK. Gender specific age-related changes in bone density, muscle strength and functional performance in the elderly: a-10 year prospective population-based study. BMC Geriatr. 2013;13(1):71.

96. Liu C, Latham NK. Progressive resistance strength training for improving physical function in older adults. Cochrane Database Syst Rev. 2009;(3):CD002759.

97. Pillard F, Laoudj-Chenivesse D, Carnac G, et al. Physical activity and sarcopenia. Clin Geriatr Med. 2011;27(3):449-470.

98. Reid KF, Fielding RA. Skeletal muscle power: a critical determinant of physical functioning in older adults. Exerc Sport Sci Rev. 2012;40(1):4-12.

99. Bean JF, Leveille SG, Kiely DK, Bandinelli S, Guralnik JM, Ferrucci L. A Comparison of leg power and leg strength within the InCHIANTI study: which influences mobility more? J Gerontol A Biol Sci Med Sci. 2003;58(8):M728-M733.

100. Hazell T, Kenno K, Jakobi J. Functional benefit of power training for older adults. J Aging Phys Act. 2007;15(3):349-359.

101. Porter MM. Power training for older adults. Appl Physiol Nutr Metab. 2006;31(2):87-94.

102. Robert-Koch-Institut. Sportliche Aktivität. Wie aktiv sind die Deutschen. Berlin, Germany: RKI; 2012.

103. Kemmler W, von Stengel S. Alternative exercise technologies to fight against sarcopenia at old age: a series of studies and review. J Aging Res. 2012;2012:109013.

104. Kaeding TS. Sarkopenie und Vibrationstraining: Eine Ubersicht. Z Gerontol Geriatr. 2009;42(2):88-92.

105. Sitja-Rabert M, Rigau D, Fort Vanmeerghaeghe A, RomeroRodriguez D, Bonastre Subirana M, Bonfill X. Efficacy of whole body vibration exercise in older people: a systematic review. Disabil Rehabil. 2012;34(11):883-893.

106. Kemmler W, Birlauf A, von Stengel S. Einfluss von GanzkörperElektromyostimulation auf das Metabolische Syndrom bei älteren Männern mit metabolischem Syndrom. Dtsch Z Sportmed. 2010;61(5): 117-123.

107. Kemmler W, von Stengel S, Engelke K, Haberle L, Mayhew JL, Kalender WA. Exercise, body composition, and functional ability: a randomized controlled trial. Am Prev Med. 2010;38(3): 279-287.
108. Kemmler W, von Stengel S. Whole-body electromyostimulation as a means to impact muscle mass and abdominal body fat in lean, sedentary, older female adults: subanalysis of the TEST-III trial. Clin Interv Aging. 2013;8:1353-1364.

109. Kemmler W, Bebenek M, Engelke K, von Stengel S. Impact of whole-body electromyostimulation on body composition in elderly women at risk for sarcopenia: the Training and ElectroStimulation Trial (TEST-III). Age (Dordrecht, Netherlands). 2014;36(1): 395-406

110. Komar B, Schwingshackl L, Hoffmann G. Effects of leucine-rich protein supplements on anthropometric parameter and muscle strength in the elderly: a systematic review and meta-analysis. J Nutr Health Aging. 2014;19(4):437-446.

111. Milne AC, Potter J, Vivanti A, Avenell A. Protein and energy supplementation in elderly people at risk from malnutrition. Cochrane Database Syst Rev. 2009;(2):CD003288.

112. Cawood AL, Elia M, Stratton RJ. Systematic review and meta-analysis of the effects of high protein oral nutritional supplements. Ageing Res Rev. 2012;11(2):278-296.

113. Tieland M, Van de Rest O, Dirks ML, et al. Protein supplementation improves physical performance in frail elderly people: a randomized, double-blind, placebo-controlled trial. J Am Med Dir Assoc. 2012;13(8):720-726.

114. Kim CO, Lee KR. Preventive effect of protein-energy supplementation on the functional decline of frail older adults with low socioeconomic status: a community-based randomized controlled study. J Gerontol A Biol Sci Med Sci. 2013;68(3):309-316.

115. Aleman-Mateo H, Macias L, Esparza-Romero J, Astiazaran-Garcia H, Blancas AL. Physiological effects beyond the significant gain in muscle mass in sarcopenic elderly men: evidence from a randomized clinical trial using a protein-rich food. Clin Interv Aging. 2012; 7:225-234.

116. Annweiler C, Schott AM, Berrut G, Fantino B, Beauchet O. Vitamin D-related changes in physical performance: a systematic review. J Nutr Health Aging. 2009;13(10):893-898.

117. Stockton KA, Mengersen K, Paratz JD, Kandiah D, Bennell KL. Effect of vitamin D supplementation on muscle strength: a systematic review and meta-analysis. Osteoporos Int. 2011;22(3):859-871.

118. Muir SW, Montero-Odasso M. Effect of vitamin D supplementation on muscle strength, gait and balance in older adults: a systematic review and meta-analysis. J Am Geriatr Soc. 2011;59(12):2291-2300.

119. Verlaan S, Bauer JM, Sieber C, Cederholm T. Muscle mass, strength, and function effects of a high-whey, leucine-enriched nutritional intervention in sarcopenic elderly in a double blind, randomised controlled trial. Eur Geriatr Med. 2014;5(Suppl 1):S75.

120. Miller CT, Fraser SF, Levinger I, et al. The effects of exercise training in addition to energy restriction on functional capacities and body composition in obese adults during weight loss: a systematic review. PLoS One. 2013;8(11):e81692.

121. Witham MD, Avenell A. Interventions to achieve long-term weight loss in obese older people: a systematic review and meta-analysis. Age Ageing. 2010;39(2):176-184.

122. McTigue KM, Hess R, Ziouras J. Obesity in older adults: a systematic review of the evidence for diagnosis and treatment. Obesity 2006;14(9):1485-1497.

123. Felix HC, West DS. Effectiveness of weight loss interventions for obese older adults. Am J Health Promot. 2013;27(3):191-199.

124. Donnelly JE, Blair SN, Jakicic JM, Manore MM, Rankin JW, Smith BK. American College of Sports Medicine Position Stand. Appropriate physical activity intervention strategies for weight loss and prevention of weight regain for adults. Med Sci Sports Exerc. 2009;41(2):459-471.

125. Jakicic JM. Physical activity and weight loss. Nestle Nutr Inst Workshop Ser. 2012;73:21-36.

126. Swift DL, Johannsen NM, Lavie CJ, Earnest CP, Church TS. The role of exercise and physical activity in weight loss and maintenance. Prog Cardiovasc Dis. 2014;56(4):441-447. 
127. Schwingshackl L, Dias S, Hoffmann G. Impact of long-term lifestyle programmes on weight loss and cardiovascular risk factors in overweight/obese participants: a systematic review and network meta-analysis. Syst Rev. 2014;3:130.

128. Bocalini DS et al. Effects of circuit-based exercise programs on the body composition of elderly obese women. Clin Interv Aging. 2012; 7:551-556

129. Wycherley TP, Moran LJ, Clifton PM, Noakes M, Brinkworth GD. Effects of energy-restricted high-protein, low-fat compared with standard-protein, low-fat diets: a meta-analysis of randomized controlled trials. Am J Clin Nutr. 2012;96(6):1281-1298.

130. Vincent HK, Raiser SN, Vincent KR. The aging musculoskeletal system and obesity-related considerations with exercise. Ageing Res Rev. 2012;11(3):361-373.

131. Villareal DT, Banks M, Sinacore DR, Siener C, Klein S. Effect of weight loss and exercise on frailty in obese older adults. Arch Intern Med. 2006;166(8):860-866.

132. Gill TM, Gahbauer EA, Lin H, Han L, Allore HG. Comparisons between older men and women in the trajectory and burden of disability over the course of nearly 14 years. J Am Med Dir Assoc. 2013; 14(4):280-286.
133. Waters DL, Vawter R, Qualls C, Chode S, Armamento-Villareal R, Villareal DT. Long-term maintenance of weight loss after lifestyle intervention in frail, obese older adults. J Nutr Health Aging. 2013; 17(1):3-7.

134. Fletcher PC, Guthrie DM, Berg K, Hirdes JP. Risk factors for restriction in activity associated with fear of falling among seniors within the community. J Patient Saf. 2010;6(3):187-191.

135. Deshpande N, Metter EJ, Lauretani F, Bandinelli S, Guralnik J, Ferrucci L. Activity restriction induced by fear of falling and objective and subjective measures of physical function: a prospective cohort study. J Am Geriatr Soc. 2008;56(4):615-620.

136. Sallinen J, Leinonen R, Hirvensalo M, Lyyra TM, Heikkinen E, Rantanen T. Perceived constraints on physical exercise among obese and non-obese older people. Prev Med. 2009;49(6):506-510.

137. Azizan A, Justine M, Kuan CS. Effects of a behavioral program on exercise adherence and exercise self-efficacy in community-dwelling older persons. Curr Gerontol Geriatr Res. 2013;2013:282315. doi: $10.1155 / 2013 / 282315$.

138. Yardley L, Donovan-Hall M, Francis K, Todd C. Attitudes and beliefs that predict older people's intention to undertake strength and balance training. J Gerontol B Psychol Sci Soc Sci. 2007;62(2):P119-P125.
Clinical Interventions in Aging

\section{Publish your work in this journal}

Clinical Interventions in Aging is an international, peer-reviewed journal focusing on evidence-based reports on the value or lack thereof of treatments intended to prevent or delay the onset of maladaptive correlates of aging in human beings. This journal is indexed on PubMed Central, MedLine,

\section{Dovepress}

CAS, Scopus and the Elsevier Bibliographic databases. The manuscript management system is completely online and includes a very quick and fair peer-review system, which is all easy to use. Visit http://www.dovepress. com/testimonials.php to read real quotes from published authors. 